\title{
21. EFFECTIVENESS OF VARIOUS CAI EDUCATION STYLES AND SUPPORT FUNCTIONS ON SELF- STUDY
}

\author{
H. Yamamoto, M. Nakayama, Y. Shimizu \\ Graduate School of Decision Science and \\ Technology, Tokyo Institute of Technology \\ ( ${ }^{*}$ Hitachi Electronics Services Co.Ltd.,) \\ 2-12-1, O-okayama, Meguro-ku, \\ Tokyo, 152 Japan. \\ Tel: +81458261260 Fax: +81458261262 \\ e-mail: yamamoto@cradle.titech.ac.jp
}

\begin{abstract}
This paper describes a comprehensive analysis of the effectiveness of four different education styles to study the enhancement of learning methods. The comparison result shows that collaborative teaching using CAI(I) is the most effective among them. Compared with face-to-face lectures there is a difference at $1 \%$ level of significance either in the group with lower scores, in the group with higher scores, or in all. The effect of "human-to-computer interactions" advocated by cognitive science was shown quantitatively. It was also found that self-study at local offices using CAI(II) was effective in reducing the time required for learning by 24\%. Comparing the effectiveness of group learning and self-study, the authors focused on self-study and developed self-study support functions on the Web.
\end{abstract}

\section{Keywords}

CAI, training effect, collaborative learning, cognitive science, Web

The original version of this chapter was revised: The copyright line was incorrect. This has been corrected. The Erratum to this chapter is available at DOI: 10.1007/978-0-387-35393-7_22 


\section{Introduction}

In these times of radical technical innovations, companies must educate their personnel on a variety of high-level subjects. A more effective education style is being called for in group learning. A different and more effective style of education employing conventional CAI would prove to be very useful. Especially, if the effectiveness of "human-to-computer interactions" is demonstrated quantitatively, it would also be particularly beneficial for furthering the study of cognitive science in the future.

With an expectation for extending educational opportunities in remote locations and for reducing the costs, the demand for distributed education has also be increased. If self-study is possible even in places unattended by instructors and the learning time can be reduced, it is expected that CAI will spread quickly. Therefore, in its implementation, an effective CAI method both in terms of scores and time is being demanded (Okamoto, 1995).

Although many studies have been performed on development and evaluation of CAI systems (Lee and Shirai, 1996), no study has evaluated the scores and learning time quantitatively with respect to the education style.

Setting up four education styles using CAI(I) which has been developed for group learning and CAI(II) which has been developed for distributed education, this study investigated the effectiveness of them on the test scores and learning time. Furthermore, it analyzed if there was a difference in the improvement in score between group learning and distributed education.

Finally, a method was studied to ameliorate the defects of distributed self-study and developed a system having new support functions for self-study.

\section{Course Contents And Education Styles}

\subsection{Course contents}

Materials for educating computer maintenance personnel are the basis upon which this study was conducted. The traditional style of classroom teaching was evaluated to compare four different educational styles in this study. This occupied approximately $20 \%$ ( 1 to 3 days) of the total time of the course. As with any computer system, similar topics are covered to gain the knowledge required to conduct preventive maintenance and troubleshooting.

\section{$2.2 \quad$ Education styles}

Four education styles were evaluated in this paper as shown in Table 1. Since the contents differ from one educational style to another, traditional lectures were conducted for comparison using the same contents. The characteristics of each educational style are also presented in Table 1. 
Table 1 Characteristics of education styles

\begin{tabular}{|c|c|c|c|c|c|c|c|}
\hline & ucati & on style & $\begin{array}{l}\text { Learning } \\
\text { time }\end{array}$ & Instructor & $\begin{array}{l}\text { Use of } \\
\text { images }\end{array}$ & $\begin{array}{l}\text { Collaborative } \\
\text { teaching }\end{array}$ & $\begin{array}{l}\text { Self- } \\
\text { study }\end{array}$ \\
\hline $\begin{array}{l}\text { Group } \\
\text { learning }\end{array}$ & (1) & $\begin{array}{l}\text { CAI(I)-based } \\
\text { schooling }\end{array}$ & Fixed & $\checkmark$ & $\checkmark$ & - & - \\
\hline & (2) & $\begin{array}{l}\text { Collaborative } \\
\text { teaching using } \\
\text { textbooks }\end{array}$ & & $\checkmark$ & - & $\bar{\checkmark}$ & - \\
\hline & (3) & $\begin{array}{l}\text { CAI(I)-based } \\
\text { collaborative } \\
\text { teaching }\end{array}$ & & $\bar{\checkmark}$ & $\bar{\checkmark}$ & $\bar{\checkmark}$ & - \\
\hline $\begin{array}{l}\text { Distribut } \\
\text { d } \\
\text { education }\end{array}$ & (4) & $\begin{array}{l}\text { CAI(II)-based } \\
\text { self-study }\end{array}$ & Free & - & $\checkmark$ & - & $\checkmark$ \\
\hline $\begin{array}{l}\text { Face-to-f } \\
\text { comparis }\end{array}$ & lec & res for & Fixed & $\bar{\checkmark}$ & - & - & - \\
\hline
\end{tabular}

$\checkmark$ : Can be used to the fullest extent. $\quad-$ : Cannot be used fully.

Group learning is shown in Table 1, with education styles (1) to (3). As shown in style (4) for distributed education, self-study using CAI(II) was conducted. In group learning, the learning period was fixed in each educational style. In distributed education, each trainee was free to take any length of time for learning. That is, the learning time differed from one trainee to another only in style (4), self-study using CAI(II).

The instructor column is marked for the group learning in the table because there is always an instructor nearby. It is not marked for the distributed education because there is no instructor. As for images, both the CAI(I) system and CAI(II) system allowed retrieving and displaying on a screen. The "collaborative teaching" column is filled in from the viewpoint of whether or not trainees could learn mutually with one another by questions and answers and other means. The self-study support refers to such functions as an online glossary and hypertext which allow trainees to have access whenever they have their own questions.

The following details each education style.

(1) Schooling using CAI(I)

The CAI(I) system provides computer control of text, still images, video and audio. This system was developed to be used in group learning. It has a courseware creation function, learning function and other functions (Yamamoto, 1993).

Actually, one CAI(I) system was provided for each person in group learning. If a trainee did not understand the method of study or had a question, the trainee could ask the instructor a question at anytime.

(2) Collaborative teaching using printed materials

This education style used only textbooks and no CAI was used. The trainees 
were divided into teams of three to four persons each. Within this team, trainees taught each other to gain knowledge and deepen their understanding.

(3) Collaborative teaching using CAI(I)

In this education style, the trainees taught each other using CAI(I). As in the collaborative teaching using printed materials, the trainees were divided into teams of three to four persons each. Each team was provided with one CAI(I) system.

(4) Self-study at local offices using CAI(II)

CAI(II) was developed aiming at a Performance Support System (PSS) (Gery, 1991) allowing learning at anytime while working on the job (Yamamoto, Aizawa, Munemoto and Suganami, 1996).

In this educational style, the trainees studied on their own at their own locations using the same personal computers as they were employed in their daily work.

(5) Lectures for comparison of education styles

The trainees studied the computer maintenance as discussed in Section 2.1. However, in an actual course, the test problems differed from one system to another because of differences among the systems in terms of the scale of the systems from large to small. Therefore, the raw test scores could not be used for comparison of education styles. For comparison, traditional, face-to-face lectures were performed using the same contents to be learned by the trainees. The education styles were analyzed and evaluated with reference to the lectures.

In this traditional style of education, the trainees were gathered in a classroom and they were taught by an instructor using textbooks and blackboard.

\section{Evaluation Methods}

The total number of trainees was 1,516. Pre-tests and post-tests were given for all the trainees to calculate the achievement score by regression (Ikeda, 1982). This achievement score by regression allows an evaluation even if two education styles provide different scores in pre-tests. An achievement score by regression, Ar, is obtained by the following equation:

$\mathrm{Ar}=\mathrm{S}_{\text {post }}-\left(\mathrm{a} \cdot \mathrm{S}_{\mathrm{pre}}+\mathrm{b}\right)$

Where, $S_{\text {post }}$ and $S_{\text {pre }}$ are the scores in the pre-test and post-test. A regression line shows the score of the post-test which is predicted from the pre-test score that a trainee could achieve. Therefore, subtracting the predicted value from the actual post-test score leaves an achievement score by regression. An achievement score by regression works as an index of the education effect. Furthermore, by finding the difference in the achievement score by regression between the CAI(I)-based collaboration teaching and education based on lectures as a deviation score

(Nakayama and Shimizu, 1993), the effectiveness can be compared between different education styles. 


\section{Results Of Evaluation}

\subsection{Comparing the deviation score in each education style}

A deviation score from traditional lectures for each educational style was found and from that was calculated how scores were improved in each education style. Figure 1 shows the results.

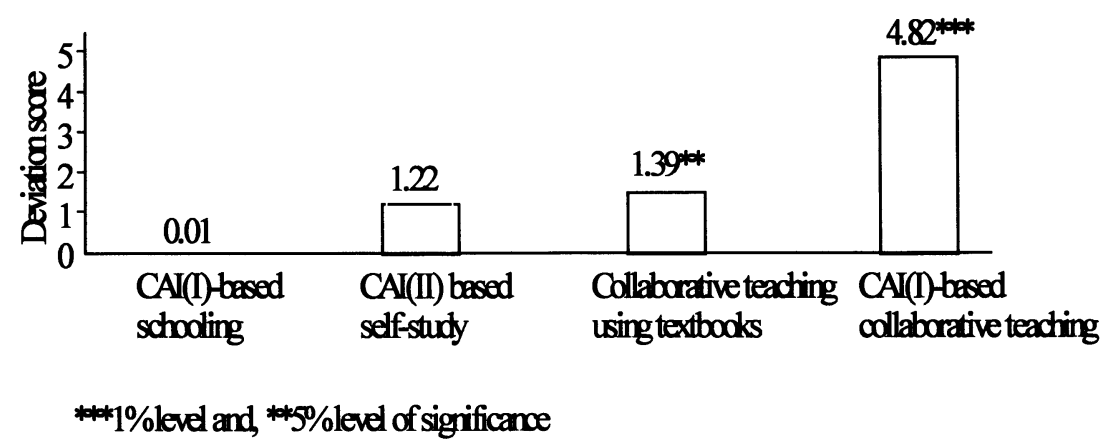

Figure 1 Deviation scores in reference to traditional lectures.

The deviation score of the CAI(I)-based collaborative teaching was 4.82 , which showed a difference at the $1 \%$ level of significance. This shows the effectiveness of the collaborative teaching where, while one trainee was engaged in learning through CAI(I), the other trainee gave their comments and questions observing the same screen. In this approach, all the trainees reflect and learn more deeply through discussion among themselves. Still pictures and video might play an important role in making the discussion more concrete and active.

The educational effectiveness of the CAI(I)-based schooling is same as traditional lectures. Although the collaborative teaching using textbooks is effective even though effectiveness is not so significant by itself. However, it was found that the two educational styles combined together is significantly effective. The effectiveness of human-to-human interaction using a computer as the medium which has been advocated by cognitive science (Anzai, Ishizaki, Ohtsuda, Hatano and Mizoguchi, 1992) could be demonstrated quantitatively. Combining education styles improved the overall effectiveness which was of great interest.

\subsection{Analyzing the group with higher scores and the group with lower scores}

To further analyze the effectiveness of each education style, the trainees were divided into a group with higher scores and a group with lower scores according to the average of the pre-test. 
The deviation score was calculated for the group with higher scores and the group with lower scores in each education style. Figure 2 shows the results.

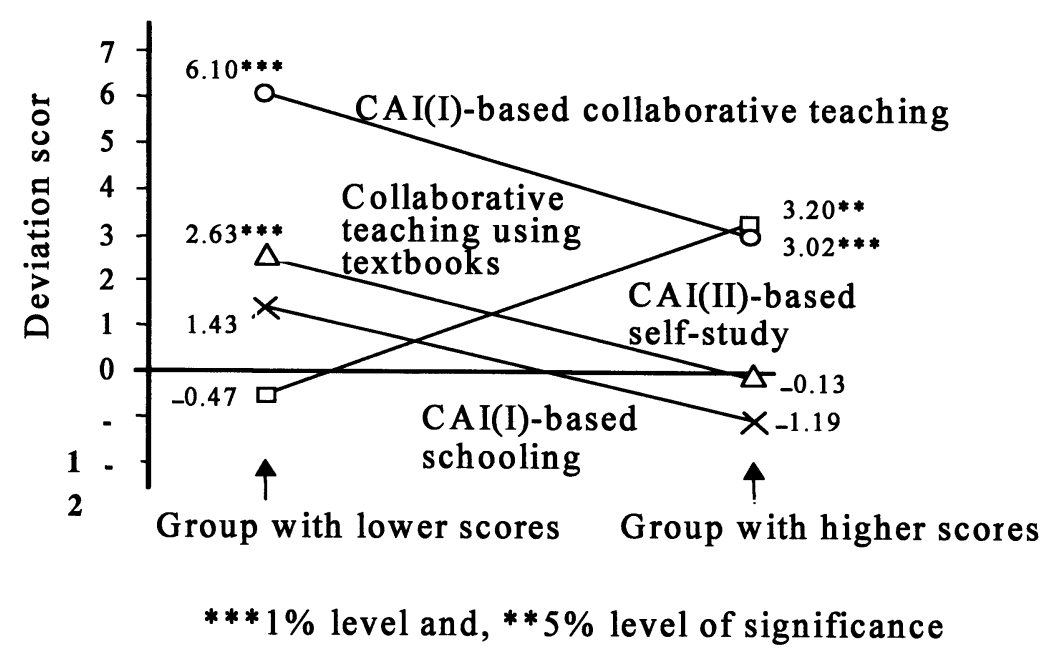

Figure 2 Deviation scores in reference to lectures (groups with higher and lower scores).

As shown in Figure 2, a higher deviation score is given by the group with lower pre-test scores than by the group with higher scores except for the CAI(II)-based self-study. Conversely, in the CAI(II)-based self-study, the group with higher pretest scores shows a higher deviation score than the group with lower pre-test scores.

Studying this result from the viewpoint of education, it would lead to a conclusion that the presence of an instructor as in a school or a situation where the trainees can ask each other questions freely is effective for the group with lower pre-test scores. However, in the distributed education as in the CAI(II)-based selfstudy, the group with higher scores could learn and build up their knowledge efficiently by making full use of the hypertext and glossary functions. On the other hand, an instructor is needed by the group with lower scores to pose questions as they arise to the group to facilitate learning. This contributed to the reason why the educational effectiveness was not improved in the group with lower scores. It was also shown by questionnaires that the group with low pre-test scores requested a software function which allowed acceptance of questions at anytime.

\subsection{Evaluation of learning time}

In the CAI(I)-based schooling, collaborative teaching using textbooks and CAI(I)based collaborative teaching, the learning time was the same as face-to-face lectures. However, in the CAI(II)-based self-study, the learning time differed from 
one person to another. Therefore, not only the test scores but also the learning times should be evaluated. The distribution of learning times are shown in Figure 3.

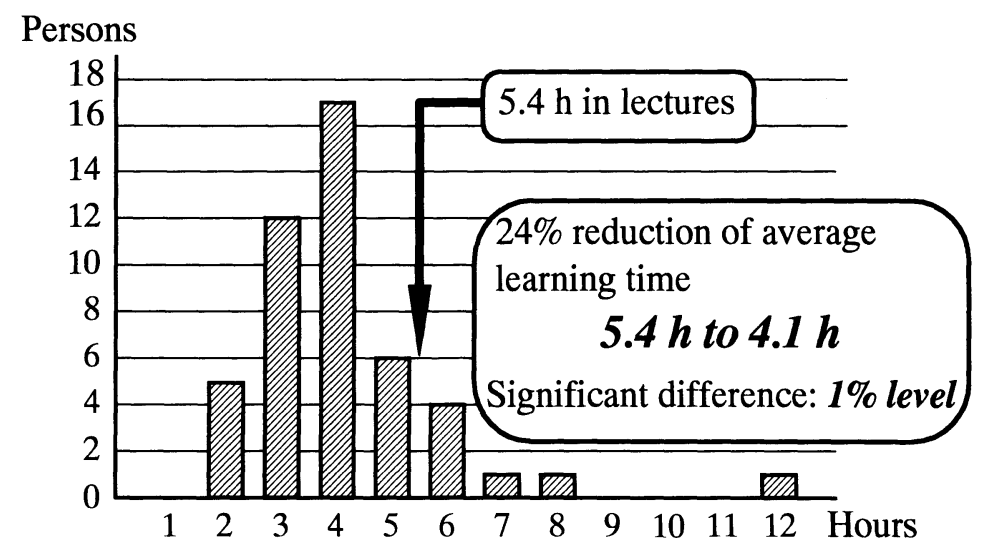

Figure 3 Distribution of learning time in CAI(II)-based self-study.

The same contents as CAI(II)-based self-study were taught in lectures lasting 5.4 hours. Compared with this time, the CAI(II)-based self-study required 4.1 hours on the average which is $24 \%$ less.

Next, the learning time was examined in the group with higher scores and in the group with lower scores.

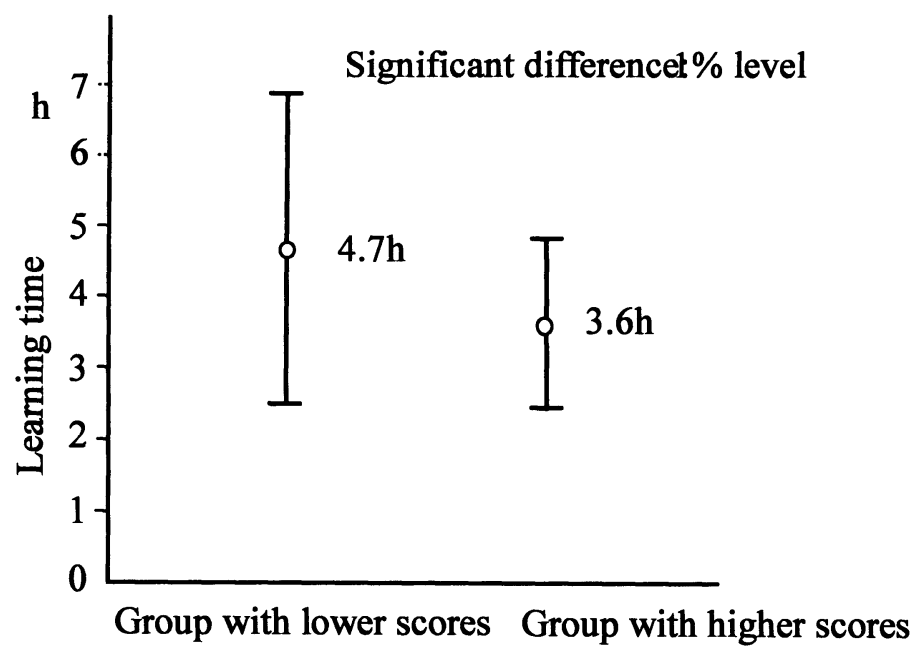

Figure 4 Learning time of the higher-scoring and lower-scoring groups. 
The self-study using CAI(II) was effective in the group with higher scores in reducing the learning time as well as the achievement scores. An analysis of the scores and learning time revealed that the support function must be strengthened for the lower-scoring group in self-study.

\section{Additional Support Functions Required For Self- Study And New System}

The support functions required for self-study based on the analysis results of the scores obtained in self-study in each workplace and the results of a questionnaire collected from the trainees and instructors were reviewed. As a result of this review, the following seven additional functions are recognized as necessary:

(1) Collaborative learning by exchanging opinions among trainees

(2) Near real-time handling of questions and answers

(3) Schedule management for education

(4) Display of a list of educational materials and access to supplementary study

(5) References such as average score, highest score and lowest score

(6) Timely distribution of educational materials

For functions (1) to (6) listed above, a Web-based CAI system using the Internet/intranet and enriched functions was developed. Figure 5 is one of the screens of the newly developed Web-based CAI system.

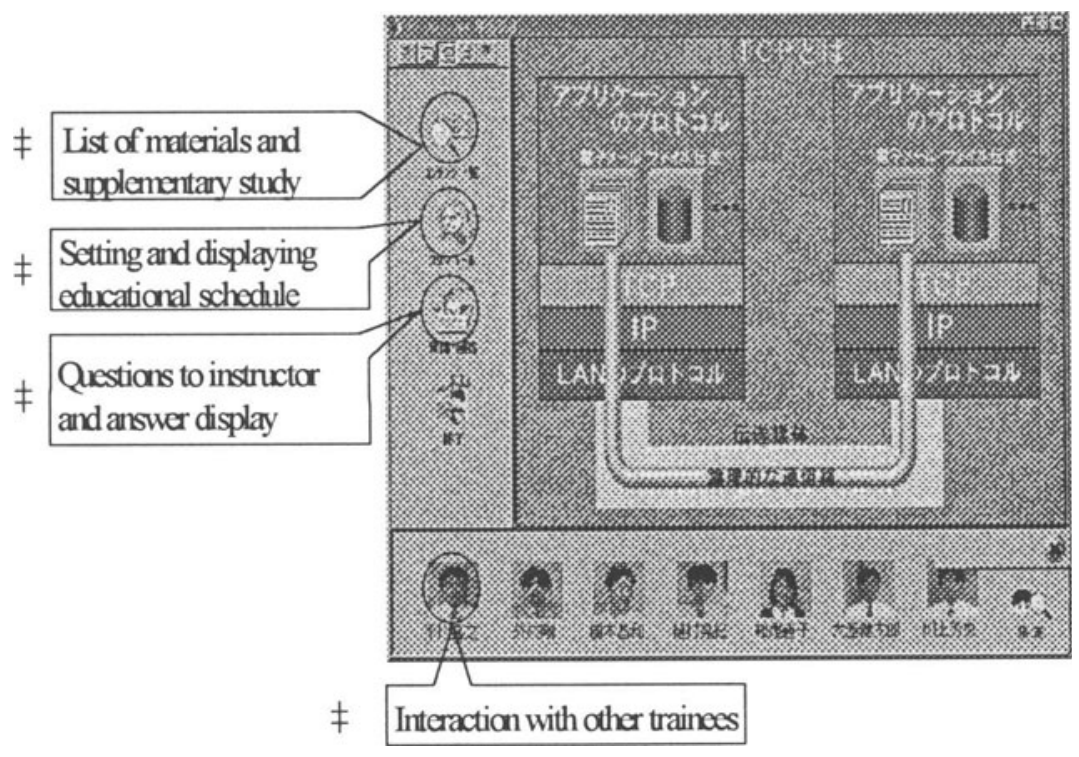

Figure 5 Web-based CAl screen. 
The major new learning functions based on Figure 5 are described in the following.

(1) Collaborative learning by exchanging opinions with other trainees This function facilitates the communication with other trainees and instructors. Not only textual information but also audio-visual communication is possible in real time. Through networking, this function is intended for providing the same environment as the collaborative teaching using $\mathrm{CAI}(\mathrm{I})$, which was effective in improving test scores. If a trainee has a question, he or she can feel free to ask it or seek an answer to it. In addition, the trainees can exchange information about their progress in the course.

(2) Questions to instructor and display of answers

This function provides a database of assumed questions, and past questions and answers and allows a user to find an appropriate answer from the database. The conventional question and answer method by e-mail required more than one day to receive an answer. This was a disincentive to trainees. In addition, time was wasted because a trainee could not proceed with the study because of lack of understanding. This function provides an answer immediately if such a question was answered in the past and stored. The user can retrieve a question just by entering a keyword; then all related items are displayed. If the question is not stored in the database, the user can request an answer by registering the question. The answers to the questions can then be given by the instructors in the education department or front-line specialists. Active learning is further enabled by an employment of this question and answer function.

(3) Setting and displaying the educational schedule

It is difficult to manage the progress of learning in self study. This function addresses this difficulty. This function can be used not only by trainees but also by instructors or managers at their workplace for reference or to give trainees advice as required.

(4) List of materials and supplementary study

This function displays a list of educational materials provided. It also allows the user to access pertinent sections in other materials or reference an easier material for reference.

(5) Other references such as average score, highest score and lowest score In group learning, trainees tend to improve themselves through friendly rivalry over each other's scores. However, in self study, a trainee is hardly conscious of other colleagues, does not set goals well and does little to maintain or improve their aspirations. In addition to including exercise problems to solidify and confirm the trainees' knowledge, the system notifies the trainees of their test scores to improve the motivation for learning.

\section{Conclusion}

(1) In the three education styles of the CAI(I)-based schooling, collaborative teaching using textbooks and CAI(I)-based collaborative teaching, the group with lower scores showed higher results than the group with higher scores at $5 \%$ level of significance. In the CAI(II)-based self-study, the group with 
higher scores improved more than the group with lower scores at $5 \%$ level of significance. The rate of improvement in test scores differed between the higher-scoring group and lower-scoring group depending on whether group learning or distributed education was used.

(2) For the learning time, the CAI(II)-based self-study cut the time required by $24 \%$ on the average, which showed a difference from traditional lectures at $1 \%$ level of significance.

Based on the analysis results above, a new Web-based CAI system was developed. Further study is needed for evaluation of this newly developed system.

\section{References}

Anzai, Y., Ishizaki, S., Ohtsu, N., Hatano, G. and Mizoguchi, F. (1992) Handbook of Cognitive Science, Kyoritsu-Shuppan

Gery, G. J. (1991) Electronic Performance Support Systems, Gery Performance Press

Ikeda, H. (1982) Tests and Measurements, in Pedagogical Collection 25, Dai-ich Hoki

Lee, K. and Shirai, K. (1996) Evaluation of the ICAI System for Assisting Speaker of Japanese to Learn Korean Writing, IEICE Journal (D-II), Vol. J79-D-II, No. 6, 1146-57

Nakayama, M. and Shimizu, Y. (1993) Using Student Scores in the Evaluation of a Communication Satellite (PINE-NET) Lecture-Plus CAI-Based Distance Learning System, Japan Journal of Educational Technology, Vol. 17, No. 2

Okamoto, T. (1995) Education, Media and Artificial Intelligence, Artificial Intelligence Joumal, 361-7

Yamamoto, H., Aizawa, T., Munemoto, T. and Suganami, K. (1996) Development and Evaluation of EPSS type CAI, Shingaku-Giho, ET95-106, 31-38

Yamamoto, H., Ohtani, A. and Kado, T. (1993) Development and evaluation of computermediated education system for customer engineers, IFIP, 205-14

\section{Biography}

H. Yamamoto received his B.Eng. in engineering from the Department of technology, Shinshu University in 1966. He then joined Hitachi Electronics Services Co., Ltd. He is now director and general manager of the Technical Education Division. Since 1998, he has been in the doctorate program of the Tokyo Institute of Technology.

Minoru Nakayama graduated with a B.S. in Science from the Faculty of Education of Tokyo Gakugei University in 1983 and completed the M.S. program in 1985. That year he became a Research Student in the Center for Research and Development of Educational Technology, Tokyo Institute of Technology. In 1990, he received a Doctorate of Engineering from the Tokyo Institute of Technology. He is currently associate professor at the Tokyo Institute of Technology. His research interest is educational technology.

Yasutaka Shimizu graduated from Tokyo Institute of Technology in 1964, and received Master and Doctor of Engineering in 1966 and 1971. Since 1969 he has been working with Tokyo Institute of Technology and is currently Professor and Dean of Graduate School of Decision Science and Technology. He was elected an IEEE Fellow "for contributions to research and development in the field of educational technology, electromagnetic compatibility, and surface acoustic waves" in 1994. 
DISCUSSION REPORTS: 